\title{
ESPADAS Y PUÑALES DEL BRONCE FINAL: EL DEPÓSITO DE ARMAS DE PUERTOLLANO (CIUDAD REAL)*
}

\author{
POR \\ IGNACIO MONTERO RUIZ \\ MACARENA FERNÁNDEZ RODRÍGUEZ \\ BLANCA GÓMEZ TUBIO \\ Mangeles Ontalba SAlamanCA
}

\section{RESUMEN - ABSTRACT}

Se presenta el estudio tecnológico de un nuevo depósito del Bronce Final aparecido en Puertollano (Ciudad Real). Compuesto exclusivamente por armas (14 espadas y puñales y un fragmento de regatón) constituye un deposito singular entre los conocidos en la Península ibérica. Se incluyen los análisis de composición mediante técnica PIXE que indican que todas las piezas son bronces binarios $\mathrm{Cu}-\mathrm{Sn}$ con bajo nivel de impurezas. Se discute sobre la funcionalidad y uso práctico de estas producciones armamentísticas.

This paper deals with the technological study of a new Late Bronce Age hoard found in Puertollano (Ciudad Real). This hoard is a singular found in the context of Iberian Peninsula due to the number of items (14 swords and daggers and 1 fragment of ferrule) and all of them are weapons. Elemental analysis by PIXE shows a CopperTin alloy with very low impurity pattern. A general comment about the real use of this weapons is included.

\section{PALABRAS CLAVE - KEY WORDS}

Deposito. Bronce Final. Armas. Espadas. Puñales. Análisis PIXE. Tecnología.

Hoard. Late Bronce Age. Weapons. Swords, Daggers. PIXE Analysis. Technology.

\section{INTRODUCCIÓN}

Entre las armas metálicas de la Prehistoria es, sin duda, la espada el principal exponente de la conflictividad social y símbolo de la figura del guerrero. Junto a las alabardas constituye uno de los primeros tipos específicos con supuesta función de combate. En la Prehistoria de la Península Ibérica la aparición de espadas se detecta en momentos avanzados de la Edad del Bronce, siendo el registro arqueológico bastante escaso (apenas una docena de ejemplares en el área argárica) hasta el Bronce Final. Sin embargo, aunque en este periodo la tipología es más variada y el número de ejemplares conocidos es mayor que en etapas anteriores, no puede decirse que sean objetos muy numerosos. A excepción del depósito de la Ría de

* Este trabajo ha sido desarrollado en parte dentro del marco del Proyecto de Investigación BHA2001-0248 «Caracterización tecnológica de la metalurgia del Bronce Final en la Península Ibérica» financiado por el Ministerio de Ciencia y Tecnología. 
Huelva con mas de un centenar de ejemplares (completos o en fragmentos) de espadas y puñales, los hallazgos de depósitos en nuestra geografía suelen ser reducidos en el número de objetos que los integran y en el caso de las espadas se trata principalmente de hallazgos individuales vinculados a vados de ríos o zonas de paso (Ruiz Galvez, 1995). En este contexto destaca la recuperación del deposito de Puertollano compuesto por 14 espadas y puñales y algunos otros fragmentos de metal. Su número, mayor del habitual en los depósitos de las tierras interiores, y su composición casí exclusiva de espadas y puñales le confieren un valor excepcional. El análisis y estudio de este conjunto nos brinda la oportunidad de reflexionar sobre la función de estas armas y sobre la tecnología metalúrgica que las fabricó.

\section{CircunstanCias DEL HALlAZGo}

El descubrimiento fortuito de 9 ejemplares de espadas por la remoción de tierras en las obras de acondicionamiento de la finca Camino de Santiago (Puertollano, Ciudad Real) y su inmediata comunicación a la Junta de Comunidades de Castilla La Mancha permitió realizar una investigación detallada sobre las circunstancias del hallazgo y completar la recuperación del conjunto de armas que forman este depósito.

La finca se encuentra situada a $700 \mathrm{~m}$ sobre el nivel del mar, en la margen derecha del arroyo de Canalcerro — según el mapa parcelario de la zona — o arroyo de Tamujoso — según el Mapa Topográfico Nacional, hoja ${ }^{\circ}$ 836, de escala 1:50.000 (Fig. 1), próximo al paraje conocido como Erillas de Calzada, a unos $2 \mathrm{~km}$ de la Dehesa de Boyal y a unos $5 \mathrm{~km}$ al sur de Puertollano. Al oeste queda el Cerro de Buenavista de $859 \mathrm{~m}$. de altitud y al este un cerro de $749 \mathrm{~m}$. Al sur se sitúa la Sierra de Puertollano, donde son abundantes los yacimientos de la Edad del Bronce Pleno y de Pinturas Rupestres Esquemáticas. Sus coordenadas geográfi-

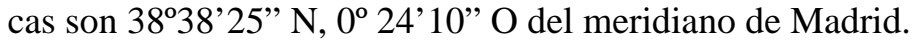

El descubrimiento se produjo exactamente delante de la fachada principal de la casa de campo, en un lugar sin pavimentar, que estaba siendo preparado para solar. Aquí, el terreno está ligeramente más elevado que el resto de la finca y en él afloraba la roca madre por dos sitios diferentes. Según testimonio de los dueños de la finca, en esta zona la roca madre afloraba hasta una altura aproximada de unos $60 \mathrm{cms}$, lo que fue aprovechado para hacer un banco corrido a lo largo de la pared de la casa. En el momento de producirse el hallazgo de las armas la máquina acababa de picar la roca de esta zona.

Se procedió a realizar una excavación de urgencia en la zona del descubrimiento con varias cuadriculas, siendo escasa la potencia sedimentaria (entre 30 y $60 \mathrm{~cm}$ ) en la mayor parte de la superficie y con presencia de residuos modernos en la capa superficial. Tan solo en las cuadricula 2 y en el testigo de esta con la cuadricula 3 se recuperaron fragmentos de una misma espada ( $\mathrm{n}^{\circ} 10$ del inventario). En el nivel superficial del corte 4, alejado de la zona del descubrimiento, apareció el fragmento de regatón. De los cortes 2 y 3 proceden la mayor parte de los fragmentos recuperados de cerámica a mano y algunos sílex. En el corte 4 también aparecieron algunos fragmentos de cerámica y antes de su excavación se recogió un hacha y una moledera de piedra.

La terrera generada en la obra fue excavada al completo. En ella se recuperaron 4 espadas, dos fragmentos de hoja que encajan con los de la espada 10 recuperados en el corte 2 y otros dos fragmentos de empuñadura. Las piezas corresponden a las inventariadas con los números «500».

Al final de la excavación el conjunto de piezas metálicas esta compuesto por 14 espadas y puñales, 1 fragmento de regatón, dos fragmentos de empuñadura que no se han podido relacionar con las espadas pero que pudieran completar alguna de ellas, y 1 fragmento de varilla que también pudo formar parte de alguna empuñadura (Fig. 2). 


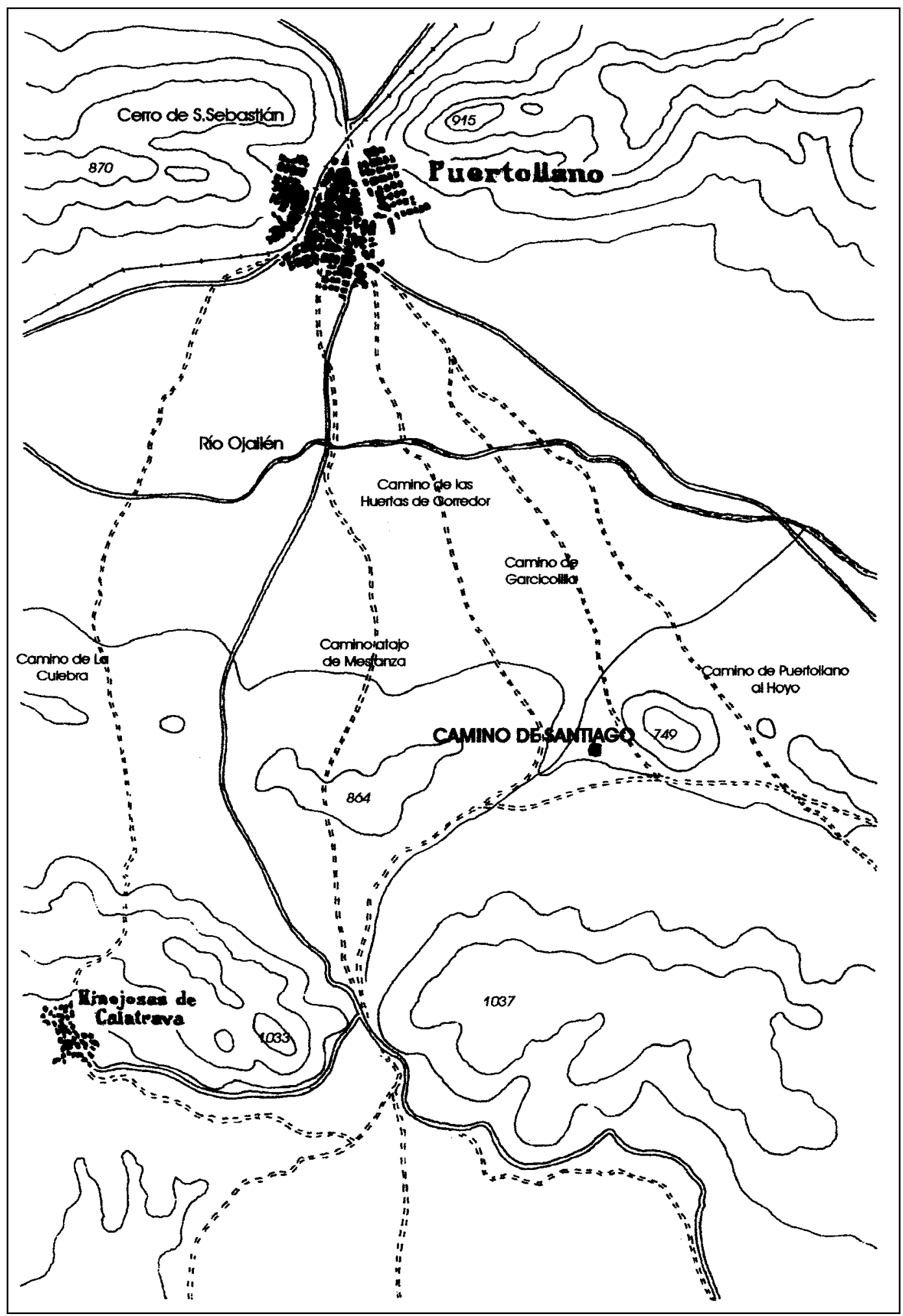

Fig. 1. Localización geográfica del hallazgo del depósito de armas de Puertollano. 


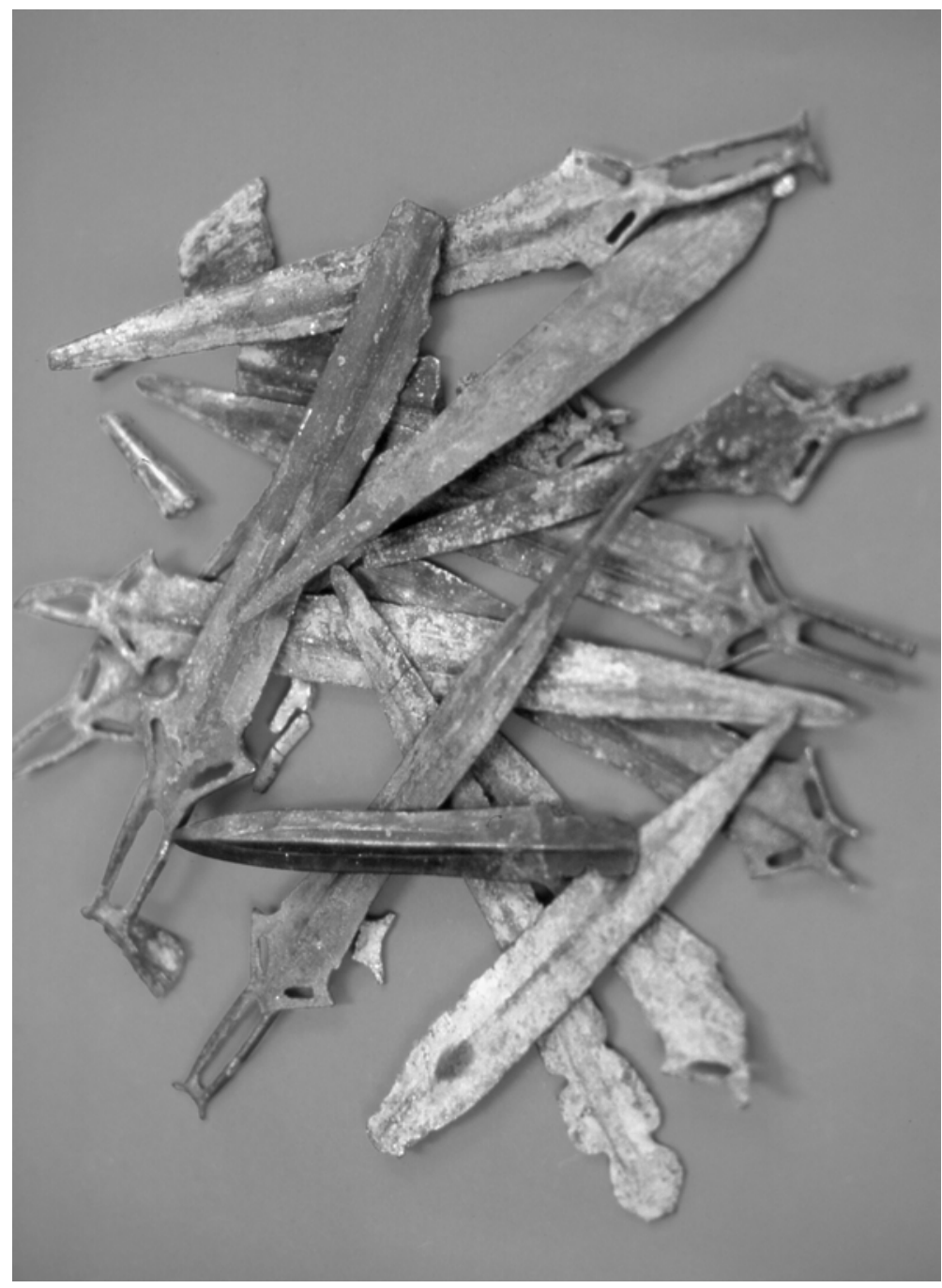

Fig. 2. Conjunto de piezas metálicas que componen el depósito de Puertollano.

En cuanto a la cerámica aparece concentrada en la zona norte de los cortes 2 y 3 . Se trata de cerámica hecha a mano, de pasta marrón rojiza, cocción mixta, desgrasantes medios y gruesos y acabado grosero. Es muy deleznable y se deshace con facilidad. Su estado de fragmentación impide determinar con precisión la forma de los recipientes. Los bordes son rectos o ligeramente entrantes, de labio redondeado, pertenecientes a cuencos y bordes exvasados de labio almendrado, correspondientes a una cazuela. Este material, junto al lítico, pertenece a un periodo anterior al de las armas metálicas, pudiendo adscribirse de manera genérica al Calcolítico. Probablemente el yacimiento se encuentre debajo de la vivienda actual de la finca, ya que algunos materiales aparecen in situ, pero sin indicios de estructuras de habitación con los que se pudieran relacionar.

La excavación arqueológica de la zona no ha permitido localizar el lugar exacto en el que fueron depositadas las piezas de bronce, lo que nos lleva a suponer que fue destruido por la máquina excavadora. Con toda probabilidad se trataba de una grieta u oquedad de la roca, o 
bien un lugar enterrado a poca profundidad entre los dos grandes afloramientos de cuarcita, que hoy han desaparecido. Si puede admitirse, en cambio, que estas piezas no fueron depositadas en el interior de ningún recipiente, sino que se dejaron directamente sobre la roca, o enterrados con algún elemento de cuero, tela o cuerdas, del que no ha quedado constancia arqueológica.

\section{DESCRIPCIÓN DEL MATERIAL}

El depósito está formado por 10 espadas, 4 puñales, 1 regatón y 3 fragmentos de empuñaduras de espadas. Las espadas tienen un tamaño inferior al normal —en torno a los $30 \mathrm{~cm}$ de media- que las sitúa en la categoría de espadas cortas. Sólo una de ellas, a la que le falta la mitad de la hoja, tendría un tamaño sensiblemente superior, en torno a los 70-90 cm. $\left(\mathrm{n}^{\circ} 4\right)$. Todas pertenecen al tipo de lengua de carpa. Los denominados puñales corresponden a espadas de lengua de carpa reutilizadas, a excepción de un puñal tipo «Porto de Mos» (nº 7). En estos casos se ha prescindido de la empuñadura original y se ha tomado únicamente la hoja, en la que se han practicado dos o cuatro hendiduras, según los casos, para facilitar el nuevo enmangue. Ninguna de las piezas conserva las cachas, que debieron ser orgánicas. Una descripción detallada del conjunto se publica en Fernández y Rodríguez de la Esperanza (2002), por lo que aquí recogemos solo los rasgos generales que más interesan para los comentarios que se realizan en el texto y las medidas.

ESPADA N $^{\mathrm{o}} 1$ : Espada de lengua de carpa (Fig 3.1)

- Sigla: 260/001.

- Conservación: Buena. La pieza está entera, salvo las cachas y los remaches de sujeción de las mismas. Tiene ligeras deformaciones en los filos. En algunas zonas presenta aspecto pulverulento, debido a la falta de consistencia de la patina.

- Longitud: $336 \mathrm{~mm}$.

- Anchura máxima guarda: $52 \mathrm{~mm}$.

- Anchura hoja: $36 \mathrm{~mm}$ junto a los ricassos y 25 en la parte central.

- Grosor máximo: $7 \mathrm{~mm}$.

- Peso: 159,03gr.

ESPADA N $^{\circ}$ 2: Espada de lengua de carpa (Fig 3.2)

- Sigla: 260/002.

- Conservación: Falta la cacha y el pomo está partido. Falta la terminación. En la fractura tiene agujeros de aire, uno de los cuales abarca prácticamente toda la sección, que es triangular. Presenta los bordes erosionados y mellados.

- Longitud máxima: $293 \mathrm{~mm}$.

- Anchura máxima guarda: $50 \mathrm{~mm}$.

- Anchura máxima hoja: $31 \mathrm{~mm}$.

- Grosor máximo: $10 \mathrm{~mm}$.

- Peso: 175 gr.

ESPADA N $^{\mathrm{o}}$ 3: Espada de lengua de carpa (Fig 3.3).

- Sigla: 260/003.

- Conservación: Sólo se conserva la parte inferior del puño. El pomo está partido y falta la terminación. Fractura elástica en la parte de la punta, justo por el lugar donde ésta se dobla. Presenta los bordes erosionados. 


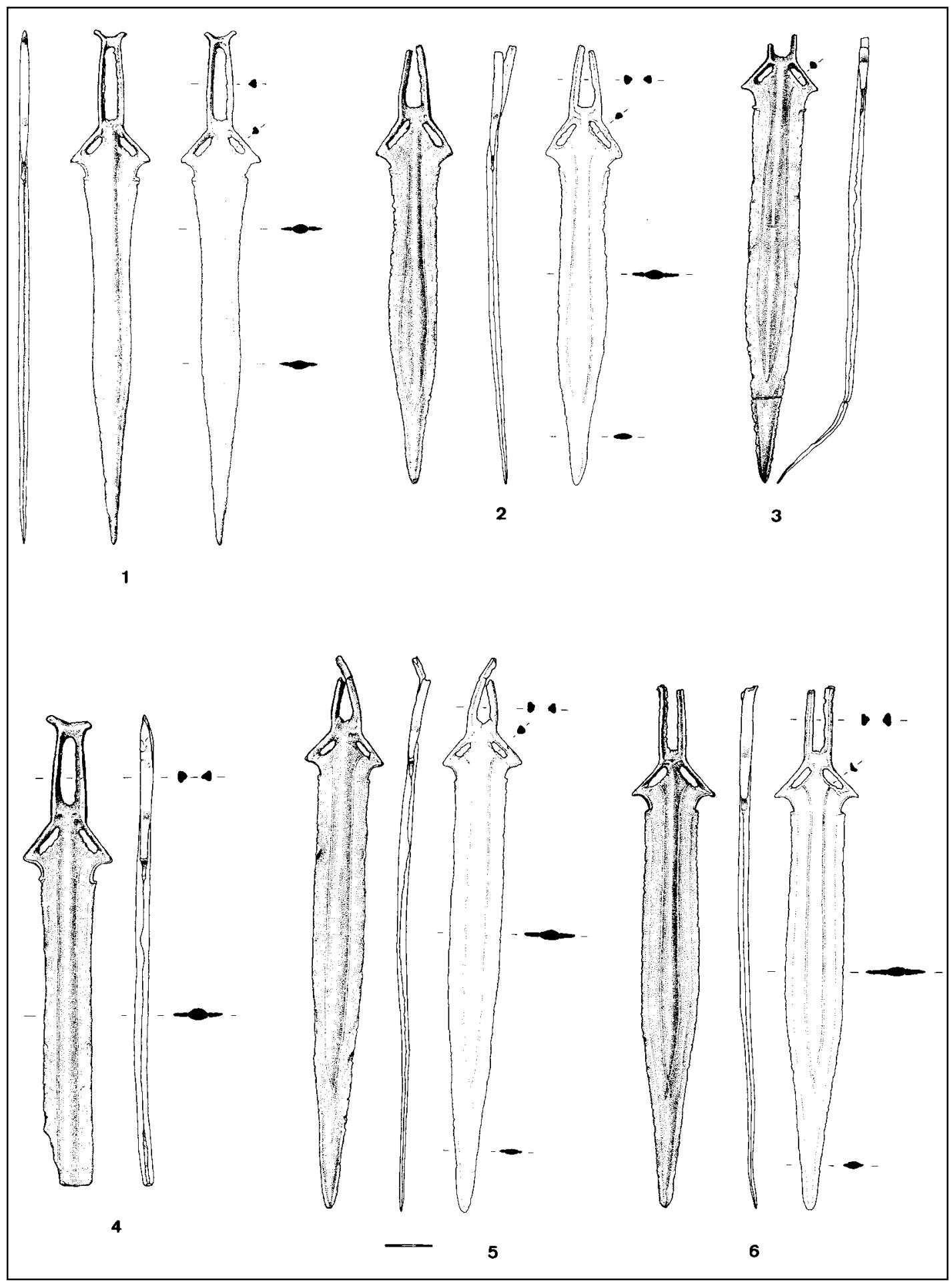

Fig. 3. Espadas 1-6. 
- Longitud máxima: $308 \mathrm{~mm}$.

- Anchura máxima guarda: $49 \mathrm{~mm}$.

- Anchura máxima hoja: $33 \mathrm{~mm}$.

- Peso: 190 gr.

ESPADA N ${ }^{\circ}$ 4: Espada de lengua de carpa (Fig 3.4).

- Sigla: 260/004.

- Conservación: Falta la cacha, aunque presenta la empuñadura prácticamente completa; el extremo izquierdo del pomo está muy gastado. Falta un trozo considerable de la punta. Tiene textura rugosa. Presenta muchos agujeros de aire en el puño, que casi lo atraviesan de lado a lado y que muestran que por algunos lados está casi hueco.

- Longitud máxima: $310 \mathrm{~mm}$.

- Anchura máxima guarda. $57 \mathrm{~mm}$.

- Anchura máxima hoja: $39 \mathrm{~mm}$ junto a la guarda y 29 en el resto.

- Grosor máximo: $8 \mathrm{~mm}$.

- Peso: 290 gr.

ESPADA N ${ }^{\circ}$ 5: Espada de lengua de carpa (Fig 3.5).

- Sigla: 260/005.

- Conservación: Bastante buena. La pieza está entera, salvo la parte terminal de la empuñadura, rota y deformada, como también lo están los filos de la hoja, que presentan pérdidas de pátina.

- Longitud máxima: $367 \mathrm{~mm}$.

- Anchura máxima guarda: $51 \mathrm{~mm}$.

- Anchura máxima hoja: $33 \mathrm{~mm}$.

- Grosor máximo: $8 \mathrm{~mm}$.

- Peso: 220 gr.

ESPADA N $^{\mathrm{o}}$ 6: Espada de lengua de carpa (Fig 3.6).

- Sigla: 260/006.

- Conservación: Buena. Faltan las cachas, el pomo, parte del puño y los remaches. En la fractura del puño se observan burbujas de aire de gran tamaño que en uno de los lados casi lo atraviesa. La hoja está ligeramente doblada hacia la derecha.

- Longitud máxima: $346 \mathrm{~mm}$.

- Anchura máxima guarda: $54 \mathrm{~mm}$.

- Anchura máxima hoja: $37 \mathrm{~mm}$.

- Grosor máximo: $7 \mathrm{~mm}$.

- Peso: 230 gr.

PUÑAL, No 7: Puñal tipo «Porto de Mos» (Fig 4.1).

- Sigla: 260/007 y 260/001.

- Conservación: Presenta una pátina noble, estable y protectora que da lugar a una superficie uniforme, con pequeñas manchas negras y pequeñas picaduras. Falta la cacha. Buen estado del núcleo metálico. La parte de la empuñadura, hasta por debajo de los ricassos está más oscura. Lengüeta de enmangue con dos entalladuras laterales para sujetar la hoja, la superior mucho más pronunciada que la inferior. Tiene dos orificios para remache, que no atraviesan la pieza por completo. Se trata de una pieza reutilizada.

- Longitud máxima: $196 \mathrm{~mm}$. 


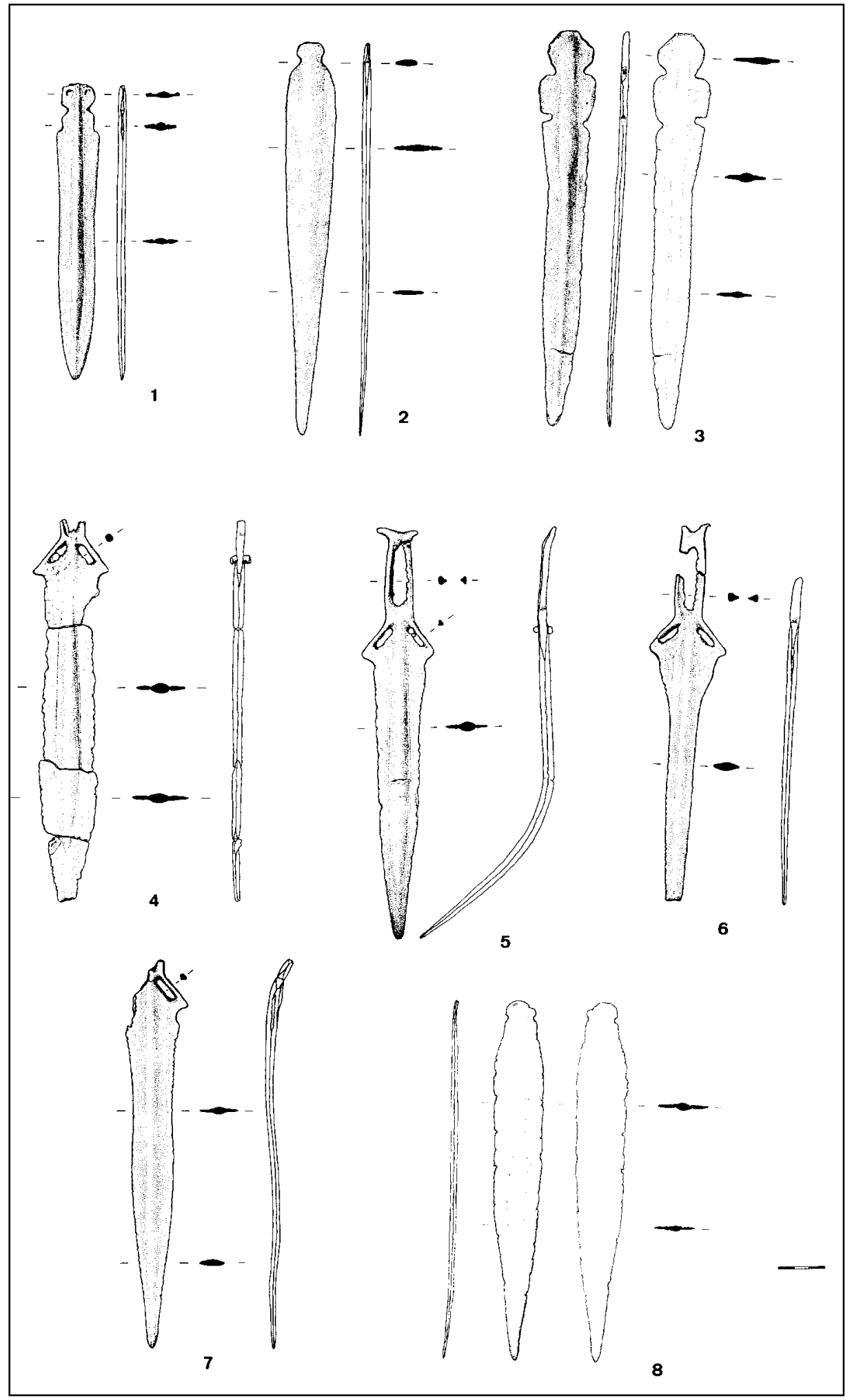

Fig. 4. Espadas 7-14. 
- Anchura máxima hoja: $28 \mathrm{~mm}$.

- Grosor máximo: $5 \mathrm{~mm}$.

- Peso: 125 gr.

PUÑAL, $N^{\circ}$ 8: Puñal en lengua de carpa (Fig 4.2).

- Sigla: 260/002.

- Conservación: Presenta una pátina noble, estable y protectora, que da lugar a una superficie uniforme, pulverulenta en aquellas zonas donde se forma una capa negra más oscura y esponjosa. Tiene una pequeñísima grieta en la parte central del extremo distal de la hoja, junto a la punta. En ésta última presenta una coloración más oscura. Lengüeta pseudocircular con extremo superior recto y dos escotaduras — una a cada ladoque marcan el comienzo de la hoja.

- Longitud máxima: $260 \mathrm{~mm}$.

- Anchura máxima hoja: $33 \mathrm{~mm}$.

- Grosor máximo: $5 \mathrm{~mm}$.

- Peso: 170 gr.

PUÑAL, $N^{\circ}$ 9: Puñal (Fig 4.3).

- Sigla: 260/009 y 260/003.

- Empuñadura: Independiente de la hoja, no conservada.

- Conservación: Lengüeta de enmangue con dos entalladuras en cada lateral para asegurar el mango. Las entalladuras son bastante irregulares, asimétricas y de distinto tamaño y están bien limadas. Filos desgastados con muescas y extremo de la punta romo. Profunda grieta en la parte distal de la hoja, que ocupa tres cuartas partes de su ancho. Tiene pátina noble, estable y protectora, que da lugar a una superficie uniforme, con pequeñas manchas negras y pequeñas picaduras.

- Longitud máxima: $263 \mathrm{~mm}$.

- Anchura máxima hoja: $31 \mathrm{~mm}$.

- Grosor máximo: $5 \mathrm{~mm}$.

- Peso: 140gr.

ESPADA N ${ }^{\circ}$ 10: Espada de lengua de carpa (Fig 4.4).

- Sigla: 101/502/505/601.

- Conservación: Está fragmentada en cuatro trozos y le falta el pomo, casi todo el puño y la punta. La superficie es rugosa y porosa, con pátina verde y marrón por la tierra, ya que está sin limpiar, tal como se halló en la excavación. Las fracturas no muestran agujeros de aire, como en otras piezas. En el extremo final de la hoja, próxima a la punta presenta una grieta muy profunda, que casi la atraviesa en sentido oblicuo.

- Longitud máxima: $253 \mathrm{~mm}$.

- Anchura guarda: $49 \mathrm{~mm}$.

- Anchura máxima hoja: $38 \mathrm{~mm}$.

- Grosor máximo: $7 \mathrm{~mm}$.

- Peso: 170gr.

ESPADA $n^{\circ}$ 11: Espada de lengua de carpa (Fig 4.5).

- Sigla: 510.

- Conservación: Conserva un remache en la guarda, pero le falta el extremo final de la punta, que parece estar cortada. La hoja se dobla hacia la mitad. Presenta tres grietas, una junto al pomo, que casi lo atraviesa, otra en el centro de la hoja, donde ésta se do- 
bla, que atraviesa el nervio central y la última, más pequeña y menos profunda, a unos $34 \mathrm{~mm}$ más debajo de a anterior. Tiene muy gastada la acanaladura central del mango.

- Longitud máxima: $310 \mathrm{~mm}$.

- Anchura guarda: $46 \mathrm{~mm}$.

- Anchura máxima hoja: 33 junto a ricassos, 28 en el resto.

- Grosor máximo: $6 \mathrm{~mm}$.

- Peso: 180 gr.

ESPADA N ${ }^{\circ} 12$ : Estoque (Fig 4.6).

- Sigla: 501.

- Conservación: El puño está fragmentado, con fractura reciente, y le falta un pequeño trozo del pomo, cuya fractura es antigua. La punta está rota de antiguo, con una rotura ligeramente cóncava, como si hubiera estado doblada. La hoja es muy estrecha, con nervio central, que nace en la guarda, sin acanaladuras.

- Longitud máxima: $249 \mathrm{~mm}$.

- Anchura guarda: $49 \mathrm{~mm}$.

- Anchura máxima hoja: $17 \mathrm{~mm}$.

- Grosor máximo: $6 \mathrm{~mm}$.

- Peso: 120 gr.

ESPADA $N^{\circ}$ 13: Espada de lengua de carpa (Fig 4.7).

- Sigla: 509.

- Conservación: La empuñadura no conserva ni el pomo, ni el puño y sólo tiene la mitad de la lengüeta y los ricassos. Le falta casi toda la empuñadura y tiene una grieta en la zona de unión de las dos acanaladuras de la guarda, que la atraviesa casi por completo. La hoja está ligeramente doblada.

- Longitud máxima: $258 \mathrm{~mm}$.

- Anchura máxima hoja: $28 \mathrm{~mm}$.

- Grosor máximo: $10 \mathrm{~mm}$.

- Peso: 140 gr.

PUÑAL, No 14: Puñal (Fig 4.8).

- Sigla: 508.

- Conservación: Falta la lenguieta. Se conservan sólo dos escotaduras laterales, una a cada lado, que son poco profundas, en torno a $3 \mathrm{~mm}$. Pero parece que pudo tener cuatro, si bien las dos de la parte inferior apenas son hoy perceptibles. La hoja ha sido recortada y progresivamene estrechada para su enmangue. El extremo final es recto y parece cortado. Presenta una pequeñísima grieta horizontal, ligeramente curva, en el centro del extremo distal, junto a la punta.

- Longitud máxima: $235 \mathrm{~mm}$.

- Anchura máxima hoja: $33 \mathrm{~mm}$.

- Grosor máximo: $5 \mathrm{~mm}$.

- Peso: 97,7 gr.

REGATÓN, No 15 (Fig 5.1).

- Sigla: 301.

- Conservación: Está incompleto por los dos extremos. En la parte superior tiene pequeñas escotaduras y presenta una grieta vertical que se prolonga hasta aproximadamente 


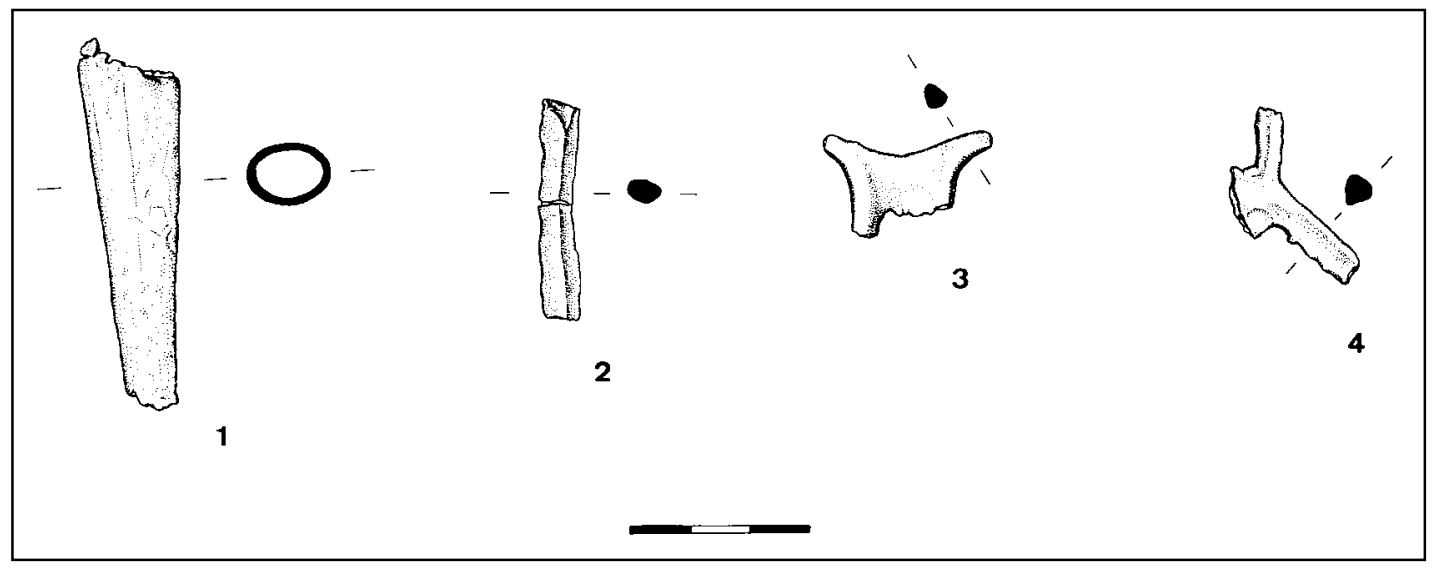

Fig. 5. Regatón y fragmentos sueltos del depósito de Puertollano.

la mitad de la pieza. El extremo final es macizo, está relleno de metal. Tiene pequeñas marcas o líneas verticales, a modo de pequeñísimas incisiones, que recuerdan la textura de un hueso. La superficie exterior es muy suave.

- Longitud máxima conservada: $60 \mathrm{~mm}$.

- Grosor máximo conservado: $17 \mathrm{~mm}$.

- Peso: 15,5 gr.

FRAGMENTO DE ESPADA n ${ }^{\circ} 16$ (Fig 5.2).

- Sigla A, N: 602.

- Conservación: Fragmento de bronce de forma alargada, de sección pseudotriangular. Probablemente perteneciente al puño de una espada. Está roto por sus dos extremos y presenta una grieta profunda, que casi lo atraviesa por la mitad.

- Longitud máxima conservada: $38 \mathrm{~mm}$.

- Grosor: $6 \mathrm{~mm}$.

- Peso: 4,5 gr.

FRAGMENTO DE ESPADA, nº 17 (Fig 5.3).

- Sigla: 503.

- Conservación: Fragmento de empuñadura de espada. Sólo se conserva el pomo, en forma de pez y el arranque del puño. Está roto por la parte inferior, en la parte del puño. Las fracturas son poco limpias y en uno de sus extremos, el más corto, el interior está completamente hueco, por un agujero de aire. Los extremos del pomo están desgastados.

- Longitud máxima conservada: $26 \mathrm{~mm}$.

- Anchura: $28 \mathrm{~mm}$.

- Grosor: $7 \mathrm{~mm}$.

- Peso: 5,6 gr.

FRAGMENTO DE ESPADA, No 18 (Fig 5.4).

- Sigla: 506.

- Conservación: Fragmento de bronce en forma de V muy abierta. Los extremos superiores tienen sección triangular y la parte inferior, donde se juntan los anteriores, es 
maciza, de forma pseudooval. Se trata del fragmento de contacto entre el puño y la guarda. La única espada que carece de esta zona es la número 13 , sin embargo ni la disposición del ángulo, ni la composición del metal encajan. Esto hace pensar en la existencia de alguna otra pieza más, con una disposición de enmangue parecida a la espada 3.Está roto por sus tres extremos, pero las fracturas son limpias y uniformes, sin agujeros de aire. Las fracturas son antiguas.

- Longitud máxima conservada: $18 \mathrm{~mm}$.

- Anchura: $33 \mathrm{~mm}$.

- Grosor: $6 \mathrm{~mm}$.

- Peso: 5,5 gr.

En las espadas de Puertollano encontramos una cierta monotonía, pero con algunas variantes. Las espadas 1, 2, 3 y 10 presentan un ligero ensanchamiento del nervio central en la parte distal de la hoja, haciendo que ésta tenga también en este punto su máxima anchura. Este ensanchamiento es menos perceptible en la espada 6 y está presente también en el nervio de la espada 11, sin que ello se refleje en la anchura de la hoja, que presenta una progresiva disminución desde los ricassos a la punta. La espada 13 a diferencia de las mencionadas, no tiene o no conserva las acanaladuras que enmarcan el nervio central. La 4 y 5 tienen la hoja con la misma anchura y, por último, la 12 es un caso diferente, ya que su hoja es excesivamente estrecha, no sabemos si porque se hizo de ese tamaño o porque se desgastó con el uso, de manera que parece más estoque que espada.

Las piezas clasificadas como puñales tampoco son iguales. Ninguno de ellos conserva las perforaciones de los remaches, aunque sí se insinúan en el 7. Dos de ellos tienen 4 escotaduras (7 y 9) (Fig. 6) y los otros sólo dos (8 y 14). Tampoco la forma de la hoja es igual en ninguna de ellas y la 8 y 14 muestran un mayor estrechamiento de la punta hasta rematar en lengua de carpa. Eso sí, todos parecen reutilizaciones de puñales o espadas anteriores. El puñal 7 es el más diferente, tanto por su reducido tamaño como por su aspecto general, ya que presenta una pátina buena y uniforme y un mayor peso en relación a su tamaño.

\section{ANÁLISIS DE COMPOSICIÓN}

Las piezas fueron trasladadas al Centro Nacional de Aceleradores en Sevilla para el estudio de su composición. Se analizaron mediante la técnica PIXE (Particle Induced X-ray Emission) utilizando la línea de microhaz externo del acelerador Tandem de 3 MV tipo Pelletron (Ontalba, 2001; Ontalba et alii, 2001). La técnica PIXE se basa en la detección de los rayos $\mathrm{X}$ procedentes de la desexcitación de los átomos tras ser ionizados por un haz de iones que proceden de un acelerador de partículas. Esos rayos X son característicos de cada átomo, de manera que resulta posible la identificación de los elementos presentes en la muestra analizada. La técnica PIXE es multielemental y de alta sensibilidad. Además, es de carácter no destructivo, especialmente cuando los análisis se realizan con la modalidad de haz externo pues, entre otras ventajas, las piezas pueden ser irradiadas directamente sin ser necesaria la extracción de muestras (Fig. 7).

En nuestro caso, las piezas fueron irradiadas con un haz de protones con una energía de 2.37 MeV sobre la muestra y una sección de unos $3 \mathrm{~mm}^{2}$. La línea de haz externo del CNA permite producir haces de iones de una resolución espacial de unos $100 \mu \mathrm{m}$, imprescindible para algún tipo de estudios, pero en este caso las regiones de análisis eran suficientemente grandes y empleamos un haz de mayores dimensiones. Para la recogida de los rayos X empleamos un detector LEGe (Low Energy Germanium), con un cristal de $5 \mathrm{~mm}$, ventana de berilio de $25 \mu \mathrm{m}$ y resolución de $135 \mathrm{eV}$ a la energía de $5.9 \mathrm{keV}$, el cual estaba situado a $43^{\circ}$ 


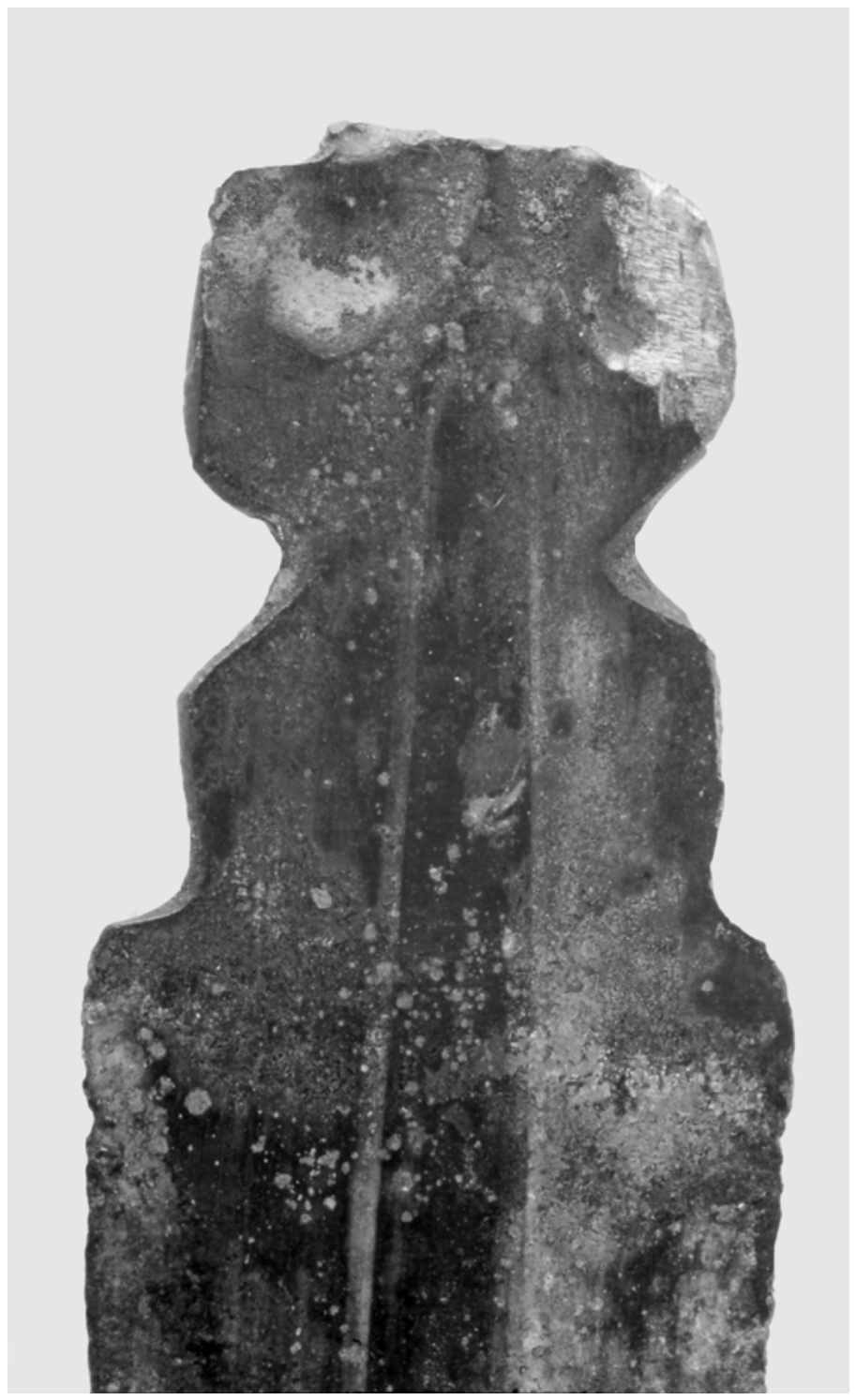

Fig. 6. Detalle de la zona de enmangue del puñal 7.

respecto a la normal a la muestra y $64 \mathrm{~mm}$ de distancia. Los elementos detectados en las muestras fueron: $\mathrm{S}, \mathrm{Cl}, \mathrm{K}, \mathrm{Ca}, \mathrm{Ti}, \mathrm{Fe}, \mathrm{Co}, \mathrm{Cu}, \mathrm{Sn}$ y $\mathrm{Pb}$ y la cuantificación se realizó mediante el programa de ajuste GUPIX (Maxwell et alii, 1995), siendo verificada mediante el análisis de patrones de bronce de composiciones certificadas. Debemos destacar que el límite de detección para el plomo se sitúa en torno al 0.1-0.15\%, por lo que no sería descartable que alguna de las piezas pudiera presentar impurezas inferiores a esos valores.

Se realizaron un total de 28 tomas analíticas. De ellas una corresponde a la patina del regatón y otra fue repetición del análisis de la espada 1. La mayoría de las piezas cuentan con dos tomas analíticas en zonas diferentes de la pieza, generalmente empuñadura y extremo de la hoja. En el caso de la espada 10 se analizó el remache y la hoja. En todos los casos se procedió a una limpieza mecánica mediante abrasivo para eliminar la patina superficial. 


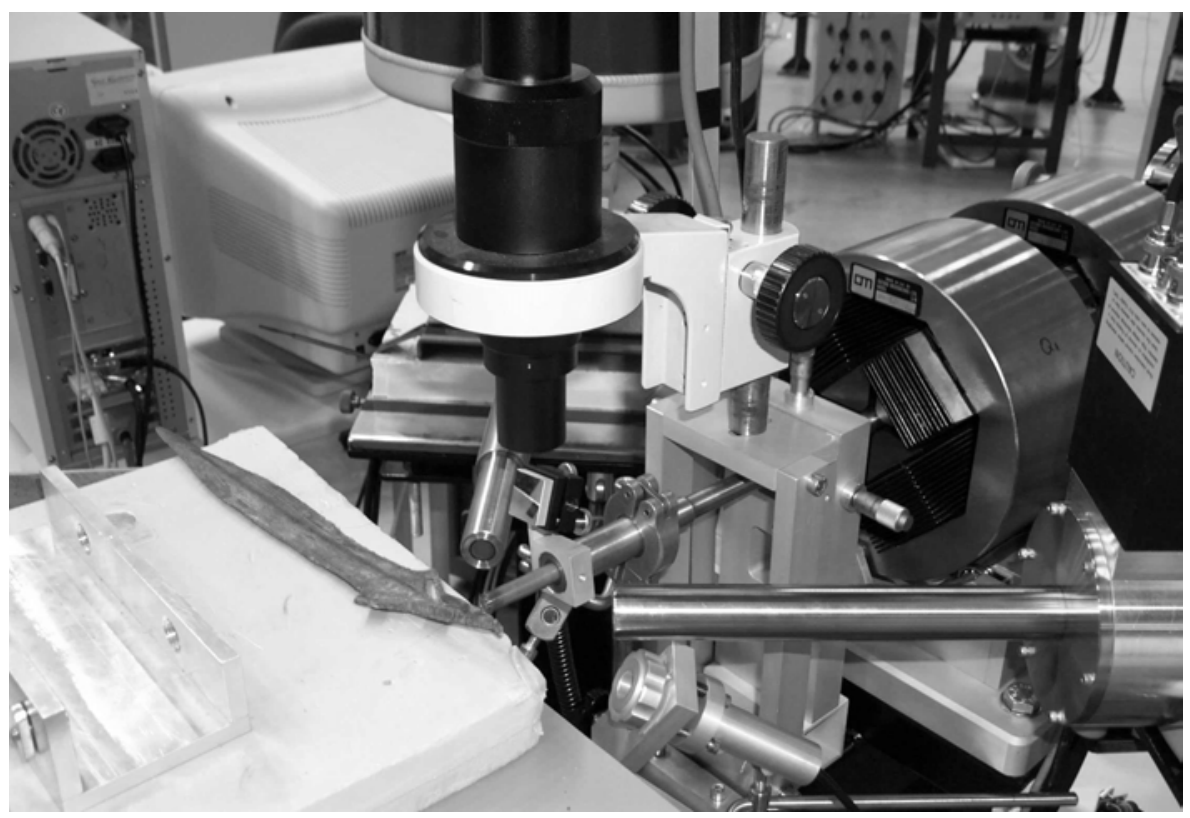

Fig. 7. Análisis en el acelerador del CNA.

TABLA 1: Concentraciones ( $\%$ en peso) determinadas por PIXE en el CNA.

\begin{tabular}{|c|c|c|c|c|c|c|c|c|c|c|c|}
\hline Objeto & Zona & $\mathbf{C u}$ & Error & Sn & Error & $\mathrm{Fe}$ & Error & Cl & Error & $\mathbf{S}$ & Error \\
\hline Espada 1 & Empuñadura & 83.9 & 0.1 & 15.3 & 0.7 & 0.027 & 0.004 & 0.22 & 0.01 & 0.11 & 0.01 \\
\hline \multirow[t]{2}{*}{ Espada 2} & Empuñadura & 87.2 & 0.1 & 12.0 & 0.6 & 0.018 & 0.003 & 0.03 & 0.01 & 0.31 & 0.02 \\
\hline & Hoja & 87.1 & 0.1 & 11.9 & 0.6 & 0.018 & 0.003 & 0.025 & 0.009 & 0.23 & 0.01 \\
\hline \multirow[t]{2}{*}{ Espada 3} & Empuñadura & 85.8 & 0.1 & 13.0 & 0.7 & 0.023 & 0.004 & 0.51 & 0.02 & 0.16 & 0.02 \\
\hline & Hoja & 84.8 & 0.1 & 14.4 & 0.7 & 0.020 & 0.004 & 0.13 & 0.01 & 0.24 & 0.02 \\
\hline \multirow[t]{2}{*}{ Espada 4} & Empuñadura & 89.9 & 0.1 & 9.3 & 0.6 & 0.018 & 0.004 & 0.09 & 0.01 & 0.16 & 0.01 \\
\hline & Hoja & 89.2 & 0.1 & 9.7 & 0.6 & 0.015 & 0.004 & 0.24 & 0.01 & 0.16 & 0.02 \\
\hline \multirow[t]{2}{*}{ Espada 5} & Empuñadura & 83.4 & 0.1 & 15.6 & 0.7 & 0.021 & 0.003 & 0.07 & 0.01 & 0.09 & 0.02 \\
\hline & Hoja & 80.2 & 0.1 & 18.8 & 0.8 & 0.009 & 0.003 & & & 0.11 & 0.02 \\
\hline \multirow[t]{2}{*}{ Espada 6} & Empuñadura & 85.2 & 0.1 & 14.1 & 0.7 & 0.016 & 0.004 & 0.07 & 0.01 & 0.16 & 0.02 \\
\hline & Hoja & 80.9 & 0.1 & 17.8 & 0.9 & 0.021 & 0.004 & 0.10 & 0.01 & 0.19 & 0.02 \\
\hline \multirow[t]{2}{*}{ Puñal 7} & Empuñadura & 87.6 & 0.1 & 11.0 & 0.7 & 0.042 & 0.004 & 0.41 & 0.02 & 0.34 & 0.02 \\
\hline & Hoja & 88.9 & 0.1 & 10.3 & 0.6 & 0.032 & 0.004 & 0.17 & 0.01 & 0.10 & 0.01 \\
\hline Puñal 8 & Enmangue & 86.2 & 0.1 & 12.7 & 0.7 & 0.018 & 0.004 & 0.39 & 0.01 & 0.13 & 0.01 \\
\hline \multirow[t]{2}{*}{ Puñal 9} & Enmangue & 86.1 & 0.1 & 13.4 & 0.8 & 0.017 & 0.004 & & & 0.18 & 0.02 \\
\hline & Hoja & 85.2 & 0.1 & 13.9 & 0.8 & 0.012 & 0.004 & 0.06 & 0.01 & 0.16 & 0.02 \\
\hline \multirow[t]{2}{*}{ Espada 10} & Hoja & 87.4 & 0.1 & 11.9 & 0.7 & 0.024 & 0.004 & & & 0.19 & 0.02 \\
\hline & Remache & 84.1 & 0.1 & 15.0 & 0.7 & 0.021 & 0.004 & 0.09 & 0.01 & 0.22 & 0.02 \\
\hline \multirow[t]{2}{*}{ Espada 11} & Empuñadura & 88.8 & 0.1 & 10.7 & 0.8 & $\mathbf{0 . 0 2 7}$ & 0.005 & & & 0.14 & 0.02 \\
\hline & Hoja & 89.6 & 0.1 & 9.53 & 0.5 & 0.025 & 0.003 & 0.07 & 0.01 & 0.14 & 0.01 \\
\hline \multirow[t]{2}{*}{ Espada 12} & Empuñadura & 84.6 & 0.1 & 13.9 & 0.7 & 0.038 & 0.004 & 0.37 & 0.01 & 0.19 & 0.02 \\
\hline & Hoja & 85.8 & 0.1 & 13.6 & 0.7 & 0.035 & 0.004 & & & 0.21 & 0.02 \\
\hline \multirow[t]{2}{*}{ Espada 13} & Empuñadura & 77.5 & 0.1 & 21.0 & 0.9 & 0.020 & 0.004 & 0.25 & 0.02 & 0.15 & 0.02 \\
\hline & Hoja & 82.4 & 0.1 & 16.4 & 0.7 & 0.014 & 0.003 & 0.16 & 0.01 & 0.20 & 0.02 \\
\hline Puñal 14 & Enmangue & 87.4 & 0.1 & 11.6 & 0.7 & 0.013 & 0.004 & 0.06 & 0.01 & 0.17 & 0.02 \\
\hline Regatón & & 96.9 & 0.2 & & & 0.020 & 0.005 & 0.91 & 0.03 & & \\
\hline Frag. 18 & & 85.7 & 0.1 & 13.4 & 0.1 & 0.049 & 0.005 & 0.10 & 0.01 & 0.13 & 0.02 \\
\hline
\end{tabular}




\section{COMENTARIOS A LOS ANÁLISIS}

Dos rasgos definen de manera general la composición de estas espadas y puñales: por un lado se trata de aleaciones de bronce binarias $\mathrm{Cu}-\mathrm{Sn}$ y por otro de un metal sin apenas impurezas de otros elementos incluido el plomo. El valor medio de estaño del conjunto es de 13.3 $\%$ con una desviación estándar de 2.7, que señala un buen agrupamiento en torno a la media. El contenido medio de estaño es algo más elevado que el conjunto de la Ría de Huelva, en el que las espadas tienen un $10.8 \%$ y los puñales de $10.6 \%$ (Rovira, 1995). Este valor medio más elevado esta condicionado por la presencia de un solo ejemplar con menos del $10 \% \mathrm{Sn}$ y sobre todo por cuatro de ellas que superan el $15 \%$. Sobre la composición de estos ejemplares nos detendremos más adelante

En cuanto a las impurezas hay que señalar que en los metales del Bronce Final de la Península Ibérica los elementos que no constituyen aleación tienen en general una presencia muy escasa, a diferencia de otras zonas centroeuropeas o atlánticas en las que en algunas etapas el arsénico, el antimonio, la plata o el plomo suelen aparecer por encima del $0.5 \%$. Así en la Ría de Huelva en un $20 \%$ de los análisis la suma de impurezas no alcanza el 0,5\% del peso, y tan solo el $6 \%$ supera el $1 \%$ en peso de impurezas, y en ellos el valor esta condicionado principalmente por la presencia de plomo. Por el contrario en algunas fases de la metalurgia inglesa o bretona varios elementos suelen superar el $0.5 \%$ en peso (Northover, 1982; Rhol y Needham, 1998).

Las impurezas de hierro son extremadamente bajas en el depósito del «Camino de Santiago» $(0,02 \%)$ y señalan que se trata de una metalurgia anterior al cambio tecnológico en el horno que introduce la colonización fenicia en el mediodía peninsular (Rovira, 1995; Orejas y Montero, 2001). En este caso la comparación de valores con los análisis del Proyecto de Arqueometalurgia (PA) debe ser indirecto, ya que la sobrevaloración de este elemento en el PA esta condicionada por la posición del pico espectral de lectura en una zona con un gran ruido de fondo, que hace más imprecisa su correcta cuantificación. El incremento de las impurezas de hierro que revela este cambio tecnológico en los analisis del PA va del $0.15 \%$ en el Calcolítico-Bronce Medio, manteniendo la Ría de Huelva un valor medio de $0.16 \%$, frente al $0.21 \%$ del conjunto de la metalurgia del Bronce Final, incluidas sus ultimas fases en las que empieza a producirse ese cambio tecnológico, y alcanza el $0.46 \%$ en la metalurgia ibérica prerromana. En la serie de análisis del British Museum el cambio se detecta en la metalurgia de época fenicia con el $0.27 \%$ frente al $0.05 \%$ Fe de los periodos anteriores (Craddock y Meeks, 1987).

Como resumen hay que decir que las composiciones del deposito de Puertollano encajan dentro del perfil general de lo conocido sobre la metalurgia del Bronce Final de la Península Ibérica. Como dato complementario, aunque poco significativo para extraer conclusiones, indicar que la espada de remaches de plata de Puertollano presenta una composición bastante similar a las piezas del depósito con una tasa de estaño de $13.9 \%$ e impurezas muy bajas (Rovira et alii, 1997: 156), pero no así con los puñales también de bronce del Cerro de San Sebastián en los que se detecta arsénico y antimonio.

Dejamos pendiente anteriormente la cuestión de los bronces con un porcentaje de estaño superior al $15 \%$. Los análisis de tres espadas con estas características son las únicas que presentan una diferencia significativa en los valores obtenidos en distintas zonas de la misma pieza (Fig. 8). Existe un cuarto ejemplar con más del $15 \%$ Sn pero dispone de un solo análisis. Creemos que estas diferencias en la composición se manifiestan por las condiciones de análisis elegidas, más que atribuirlas a una elevada heterogeneidad en la colada metálica empleada, a las condiciones en que se realizó esta, o al efecto de reparaciones de las piezas. En efecto Rovira (1995) señala unos cuantos casos de espadas de la Ría de Huelva que presentan diferencias en el porcentaje de estaño en una misma pieza, con un valor superior en la 
zona de reparación, generalmente correspondiendo a la zona de enmangue. Estas reparaciones se realizaron mediante sobrefundido, siendo necesario un metal con un punto de fusión algo más bajo para evitar dañar la zona de contacto entre las partes a unir. Esto se consigue fácilmente aumentando el porcentaje de estaño aleado. Un caso similar lo tenemos también, además de en la espada sevillana de Herrera citada por Rovira, en la de Villaverde de la Chiquita (León) en la que la empuñadura reparada presenta 3.5 \% más de estaño que la hoja (Delibes et alii, 1999: 64). Las reparaciones se identifican bien visualmente porque siempre queda una línea de costura perceptible en la unión. En ninguna de las espadas y puñales de Puertollano se observa esta circunstancia por lo que hay que descartarla. Además en dos de los casos el metal con más estaño corresponde, contrariamente a lo esperable, a la zona de la hoja.

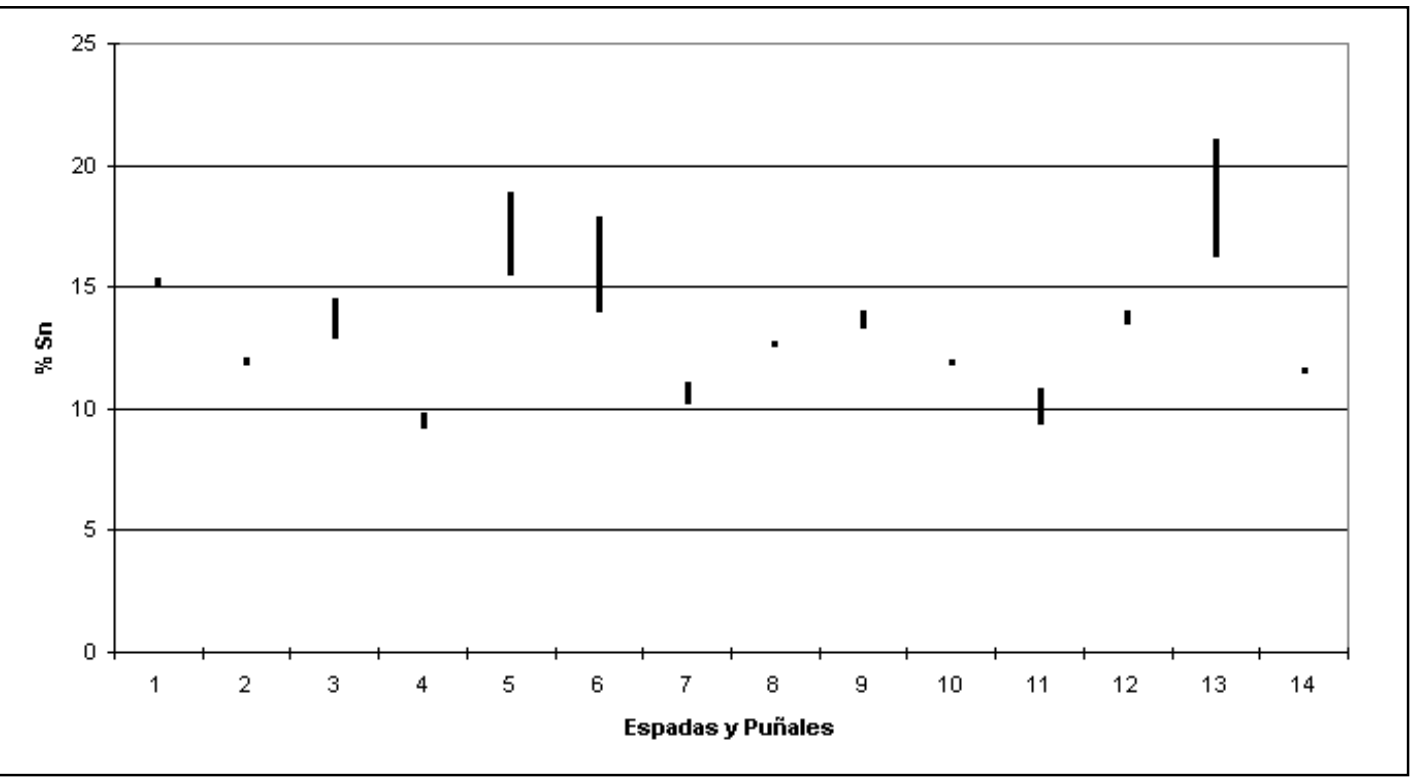

Fig. 8. Variabilidad en la composición de los objetos del depósito de Puertollano.

La heterogeneidad en la composición debe, por tanto, responder a las características del metal. En este sentido, las segregaciones se producen por la formación de diferentes fases metálicas durante el propio proceso de colado al molde al enfriarse el metal, generando la típica estructura dendrítica. Esta segregación se puede eliminar o disminuir mediante la recristalización del metal por recocido térmico, excepto cuando la aleación es rica en estaño ya que el límite máximo de solubilidad en solido está en torno al 14-15\%, lo que inevitablemente formará diferentes fases. Por encima de ese porcentaje siempre aparecen aleaciones eutécticas (Tylecote y Northover, 1990: 90). El análisis PIXE al haberse realizado en área muy pequeña puede reflejar esta formación de segregados, como indican Northover y Rychner (1998: 31) que se produce especialmente en bronces ricos como los que nos ocupan.

Las diferencias se reducen notablemente cuando las composiciones de la aleación son inferiores al $15 \%$, pudiendo en esos casos obedecer entonces a un metal que mantiene una estructura de fundición sin tratamiento posterior. En nuestro caso las espadas 3 y 11 que presentan diferencias en los resultados por encima del $1 \%$ podrían explicarse de este modo, sin olvidar que el margen de error del propio análisis (5-7 \%) relativiza la posible diferencia. No disponemos de metalografía que confirme la técnica de manufactura de estas piezas, pero 
como veremos a continuación no es infrecuente la aparición de espadas sin tratamientos posteriores a su fundición.

La hipótesis de que las diferencias detectadas en los análisis de una misma pieza se deban a las condiciones del análisis se ve reforzada por algún otro resultado obtenido en el Proyecto de Arqueometalurgia. La técnica empleada fue el análisis por EDXRF en área $\left(80 \mathrm{~mm}^{2}\right)$ lo que minimiza el efecto de la segregación. Así en la espada de Carboneras de Guadazaón (Cuenca) con un bronce muy rico los análisis realizados en empuñadura y hoja apenas se diferencian en un 0,6 \% (Díaz Andreu y Montero, 1998: 43).

El que, como ya indicamos, la aleación de mayor contenido en estaño pueda aparecer tanto en la empuñadura como en la hoja nos hace pensar que la heterogeneidad no es consecuencia de las condiciones de colado que favorezcan una mayor tasa de estaño en las últimas partes del molde rellenadas (normalmente la empuñadura), como suele ocurrir en las aleaciones de bronce muy plomadas con la gran segregación del plomo.

Para terminar con las composiciones debemos comentar el resultado del fragmento de regatón. Es un cobre sin alear y presenta pequeñas trazas de plomo, por lo que se diferencia del resto de los metales del conjunto. Se trata de una composición realmente excepcional para una pieza del Bronce Final, donde los cobres sin alear son minoritarios y aparecen en elementos como, por ejemplo, algunos punzones en el Peñon de la Reina (Almería) (Rovira y Sanz, 1983) o en un par de remaches de la Ría de Huelva (Rovira, 1995). No hay ningún otro regatón entre los analizados por el Proyecto de Arqueometalurgia que sea de cobre; todos son de bronce binario.

\section{TÉCNICAS DE MANUFACTURA}

Existen suficientes datos que certifican la elaboración a molde de espadas y puñales durante el Bronce Final. Tanto los fragmentos de moldes de piedra y arcilla como las metalografías indican que la forma definitiva del objeto se obtenía de este modo. Con posterioridad se podía aplicar tratamiento de forja y recocido para endurecer el metal, especialmente en los filos, sin embargo en algunos casos no se realizó modificación alguna. Así lo atestigua, por ejemplo, el estudio general de Brigford (1998) sobre espadas inglesas del Bronce Final o el más concreto del depósito de Petters (Tylecote y Northover, 1990).

Los tratamientos seguidos, junto con la composición, condicionan la dureza y resistencia final del metal. La falta de tratamientos posteriores a la fundición inevitablemente produce espadas blandas. Lo mismo ocurre cuando el tratamiento último es el recocido con una buena homogeneización del metal. Aunque en la mayoría de ellas se producen o forjas selectivas de los filos o tratamientos completos de forja+recocido+forja la variabilidad en la dureza conseguida es muy grande. No son frecuentes los estudios sobre dureza en metales prehistóricos pero los datos disponibles del estudio de las espadas inglesas revelan que los tratamientos aplicados no apuran el máximo de posibilidades que la aleación ofrece, posiblemente porque una mayor dureza produce también un metal más quebradizo. Sin embargo, los valores oscilan entre 110 y $250 \mathrm{HV}$ sin contar con las piezas no trabajadas o dejadas en estado de recocido, con las máximas frecuencias entre 130 y $190 \mathrm{HV}$, lo que muestra una notable diferencia en la calidad de las mismas. El bronce, sin embargo, se encuentra a una gran distancia de la dureza que se consigue con el hierro y el acero, que dependiendo de la cantidad de carbono (0.5-1\%) oscilará entre 500 y 1000 HV (Scott, 1987: 114).

Sin embargo, existe un factor más determinante que la dureza a la hora de valorar la función de estas armas. Nos referimos a la propia calidad de la fundición y a la presencia de gases o burbujas en el metal. Este es un aspecto esencial a la hora de producir la rotura de la pieza pero que, sin embargo, no es visible externamente a menos que la pieza esta rota. La 
presencia de estas burbujas crea una gran fragilidad al metal, especialmente en zonas de poco grosor como son los enmangues. El depósito de Puertollano nos permite apreciar bien la importancia de este fenómeno. La espada $\mathrm{n}^{\mathrm{o}} 6$ que presenta un excelente estado de conservación tiene fracturada la parte superior del pomo y son visibles las porosidades, y en uno de los lados casi toda la superficie esta ocupada por una burbuja. La espada 2 presenta una situación similar. La pieza esta completa y en buen estado de conservación pero con fractura en la parte superior del puño en la que se observan grandes porosidades. En el caso de la espada 4 los poros son visibles en el metal del puño, aunque todavía no esta fracturado (Fig. 9). También son claros los defectos de fundición en el fragmento de empuñadura 17, uno de cuyos lados está ocupado por una gran burbuja (Fig. 10).

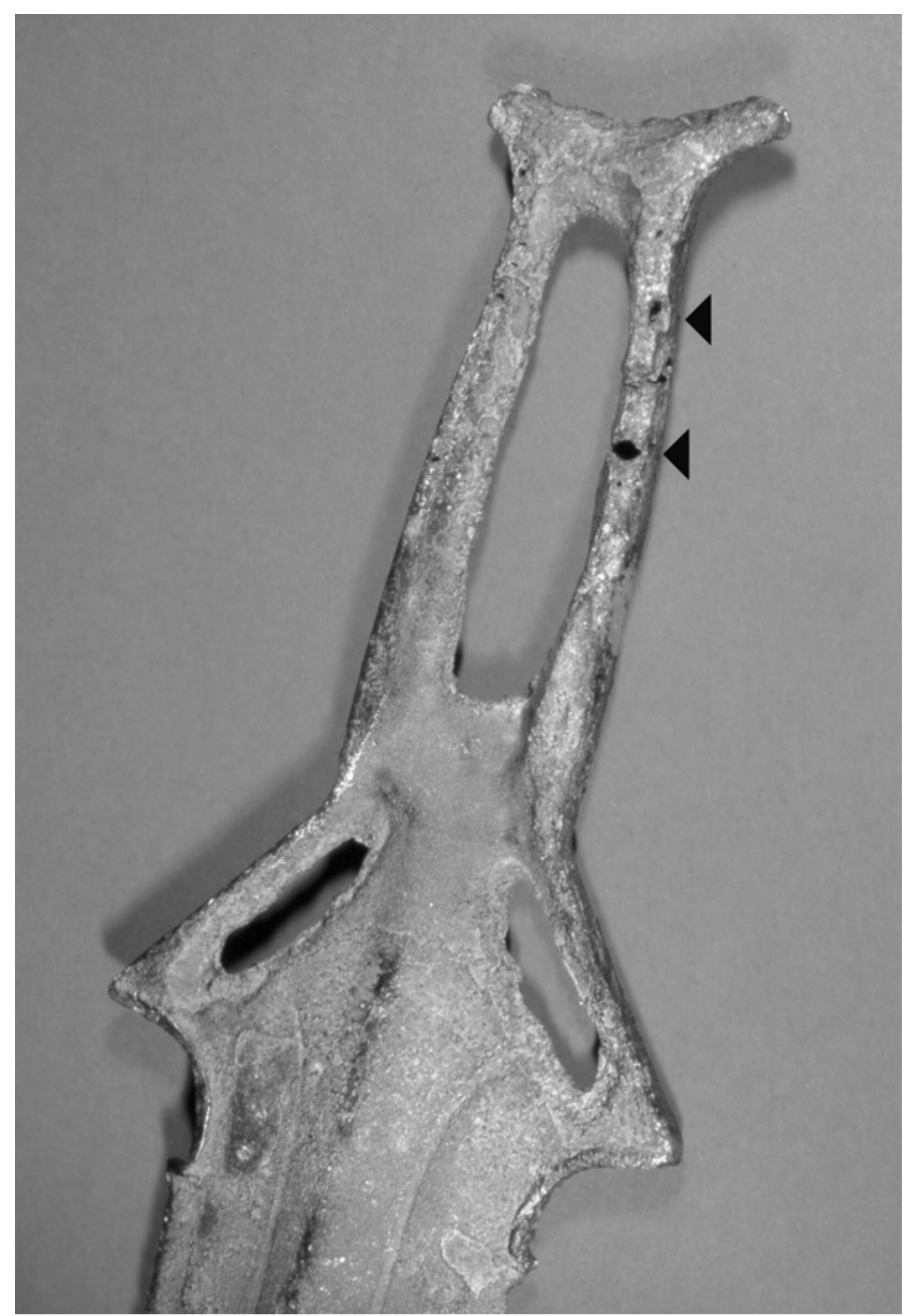

Fig. 9. Detalle de la empuñadura de la espada 4 mostrando porosidades de fundición. 
En la Ría de Huelva una gran cantidad de ejemplares presenta zona de rotura en las partes del puño. Las fracturas en la hoja o la punta también pueden ser consecuencia de esta presencia de burbujas como se detecta en algunas metalografias practicadas.

El desgaseo del molde es un problema no bien resuelto en la metalurgia del Bronce Final, donde el tamaño de las piezas como las espadas y/o el volumen de metal empleado, como en las hachas, hace complicado la obtención de una fundición sana. Como comenta Rovira (1995: 49) en parte de los moldes conocidos no existen canales de desgaseo para atender esta necesidad y en el caso del molde de Ronda además sus caras planas ajustan muy bien, lo que entorpece aún más la evacuación de gases. Rovira menciona también los experimentos sobre fundición de espadas de Tylecote (1973) en el que se demuestra que los mejores resultados se obtienen con malos ajustes de valvas y sin cubriciones de arcilla externas.

Aunque la metalografía no es tan frecuente como los análisis de composición disponemos de suficiente información para valorar la frecuencia de fundiciones defectuosas, aunque el registro de las completamente fallidas sea muy restringido ${ }^{1}$, ya que al detectarse el error al terminar la operación, ya sea por rotura inmediata o por observación de los defectos, el metal pudo ser recuperado.

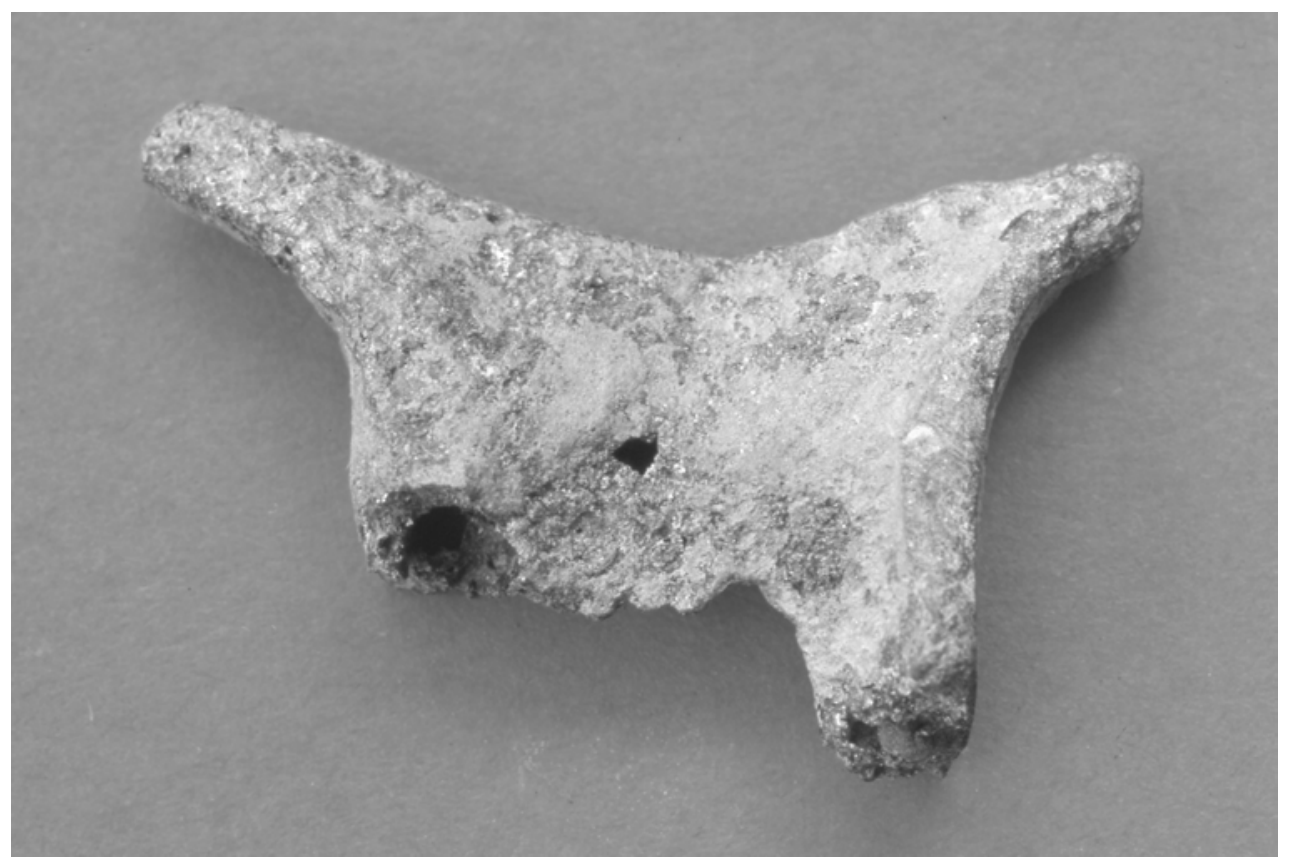

Fig. 10. Fragmento de empuñadura $n^{\circ} 17$ en el que se observa el hueco de una burbuja en la zona de fractura.

En el depósito de Petters (Tylecote y Northover, 1990) existen 35 piezas con metalografía de las que el $37 \%$ muestra presencia de gases en el metal, y en cuatro de ellas el tamaño de las burbujas es considerablemente grande. Si nos ceñimos únicamente a las espadas, de las 10 estudiadas en 4 se detectan los gases, manteniendo la proporción cercana al $40 \%$ del

1 Un ejemplo de esta situación lo tenemos en un hacha de apéndices laterales de Arroyo Manzanas (Toledo) que se fracturo en su zona media al salir del molde, ya que aún conserva las rebabas de la fundición (Montero, 2001). 
estudio de conjunto. En las metalografías de las piezas de la Ría de Huelva la proporción es algo mayor para las armas (espadas, puntas de lanza y regatones) con un $50 \%$ de piezas con presencia de porosidades. En el resto de objetos menores también hay algún caso con numerosas burbujas. Dos de las 4 espadas metalografiadas presentan grandes burbujas a las que se considera responsable de la rotura (Rovira, 1995: 49-52). Un tercer conjunto con menor número de piezas metalografiadas es el de la colección Fontaneda (Delibes et alii, 1999), en este caso la proporción de metales no sanos sería del $43 \%$. Además disponemos de otras piezas sueltas metalografiadas que confirman la frecuencia de la presencia de burbujas en estas producciones. Este es el caso del fragmento de espada del depósito de Llavorsí (Consuegra et alii, 1991) y del fragmento de espada de Castrejones (Hunt, 1997: 356), o las llamativas radiografías de las hachas del depósito de Samieira en el que se aprecian grandes huecos en el interior de las mismas (Sierra, 1984).

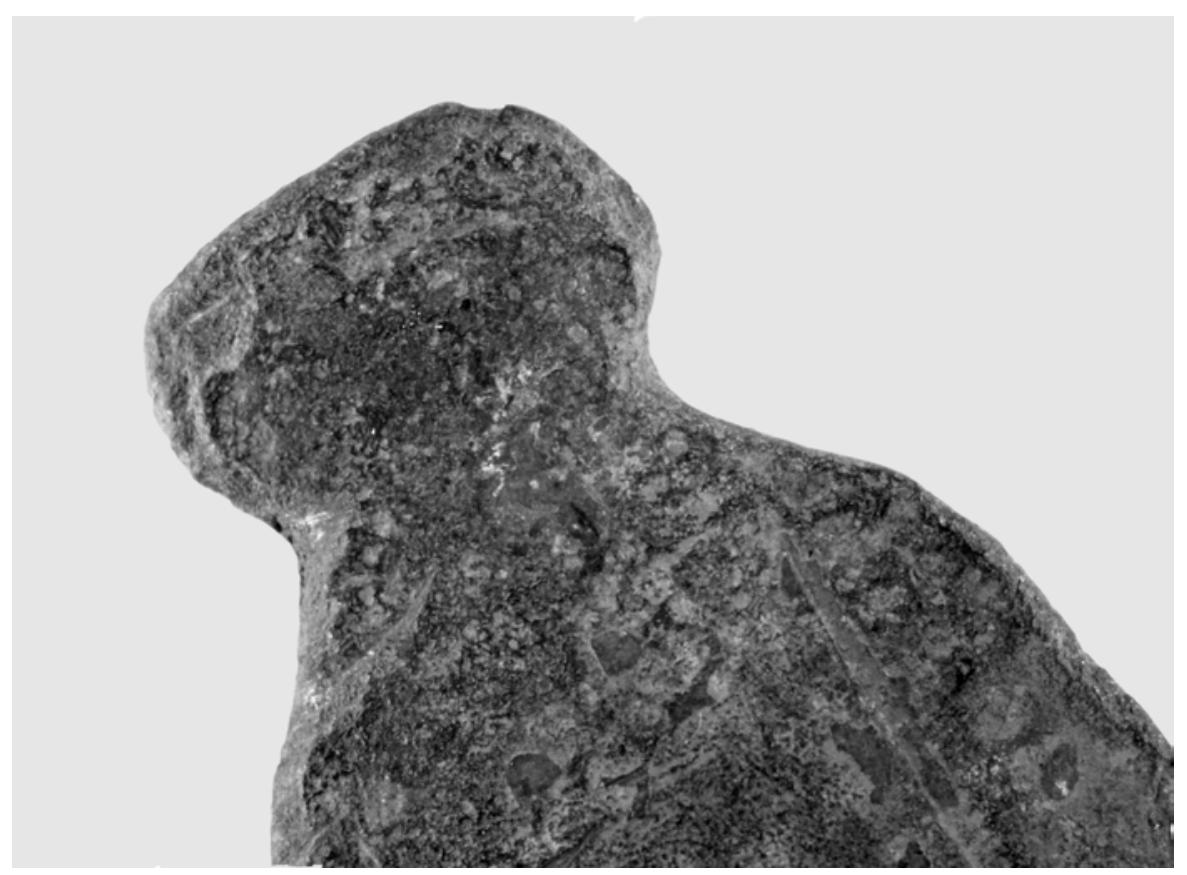

Fig. 11. Detalle de las modificación de la hoja para crear escotaduras del puñal 8.

Atendiendo a los resultados comentados podemos asumir que entre un 40-50\% de las piezas pueden presentar problemas de fundición, en algunos casos muy severos, que condicionan su vida útil.

La rotura de una espada o puñal permite tres posibles actuaciones: 1. Reparación mediante sobrefundido; 2 . Modificación de la pieza y 3. Refundición del metal.

Las reparaciones no son demasiado habituales entre el material conocido, aunque se han descrito varios casos como comentamos anteriormente. La parte reparada suele ser el enmangue en la zona del puño y la guarda. Algo más habitual es modificar la forma original de la pieza para adaptar un nuevo sistema de enmangue que sustituya al fracturado. En estos casos se elimina toda la zona superior y se trabaja a partir de la hoja creando escotaduras o una lengüeta como nueva forma de enmangue. En el depósito de Puertollano los ejemplares 7, 8, 9 y 14 responden a esta situación. La consecuencia principal es un acortamiento de la 
longitud original de la pieza. Las variaciones en el tipo de modificación son enormes, así en el puñal 9 las escotaduras son dobles y con una marcada asimetría, las modificaciones parecen afectar también a la zona de la punta, que no corresponde con el de la pieza original si nos fijamos en la disposición de la nervadura central. En el puñal 8 las acanaladuras nos indican que la modificación se realizó en una parte más central de la hoja (Fig. 11).

La zona de fractura y el número de estas condiciona las posibilidades de reutilización del objeto, aunque la casuística es variada como hemos visto. Así la espada 10 que presenta varias roturas antiguas (Fig. 12) sería un caso en el que no se puede reconstruir un puñal porque ninguno de los fragmentos reúnen el tamaño conveniente para ello. El metal en estos casos podría ser reamortizado en una nueva fundición. Pero lo importante aquí es llamar la atención sobre la elección de modificación y aprovechamiento del metal original antes de destinarlo a refundición. Incluso en ciertos casos se prefiere reparar la espada con un sobrefundido, técnica compleja de ejecución pero que indirectamente asegura el uso de una hoja bien fundida ante el elevado riesgo de porosidades que significa la fundición completa de una nueva pieza. Este es un comportamiento muy interesante que debe tenerse en cuenta a la hora de establecer modelos de circulación de metal (Needham, 1998) y para considerar la función de uso de los objetos.

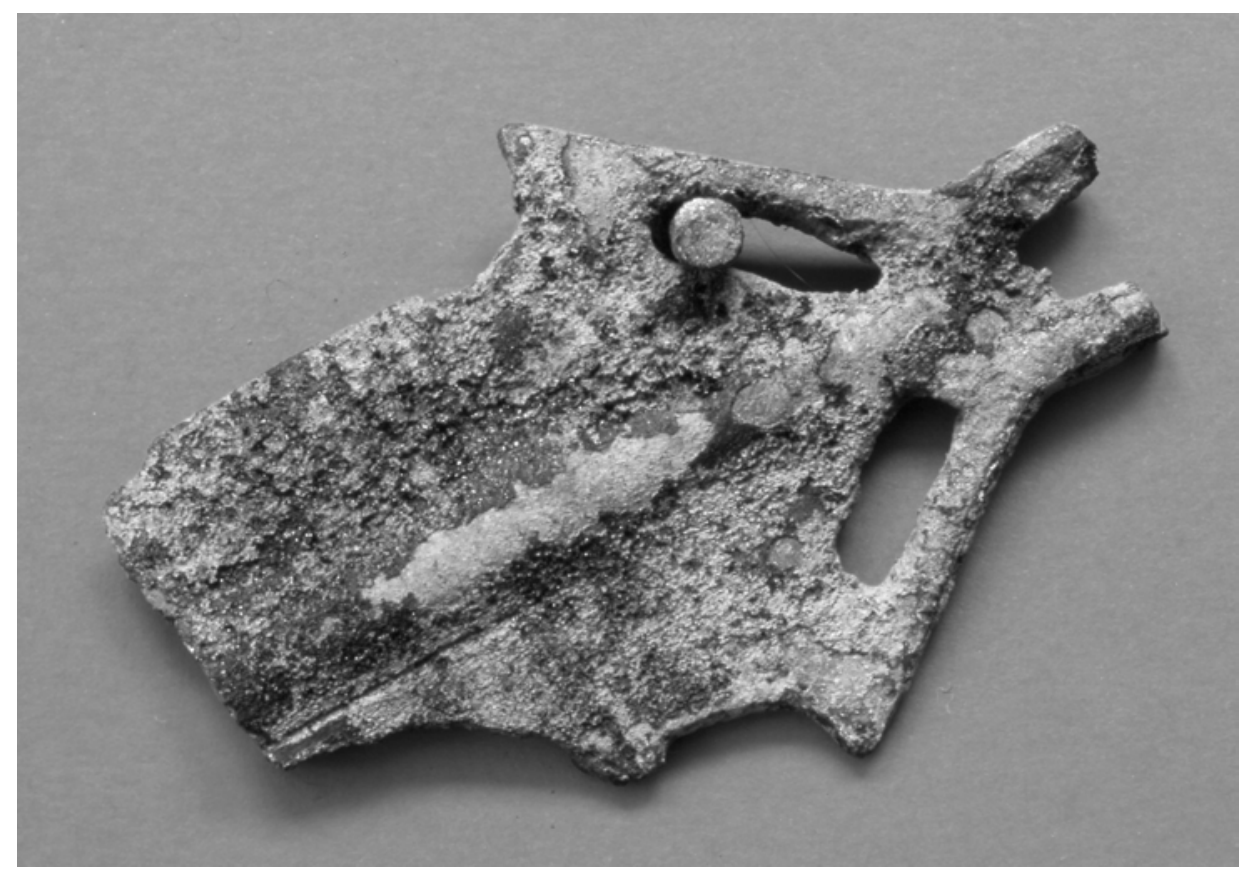

Fig. 12. Fragmento de la espada 10.

\section{VALORACION FINAL}

El deposito de Puertollano amplia el número de los depósitos del Bronce Final conocidos en la Península Ibérica. Al margen del número de objetos que lo componen, superior a la media, en este caso se trata además de un conjunto exclusivo de armas: espadas cortas, puñales y un fragmento de regatón que rompe la uniformidad del conjunto. Este último elemento, recuperado en una zona alejada de la zona de deposición original, es también diferente por su 
composición al resto del conjunto. La ausencia de cualquier otro elemento arqueológico vinculado al Bronce Final hace que debamos considerarlo como parte del depósito.

Si observamos la formación de aquellos depósitos que cuentan con más de 10 objetos nos damos cuenta que incluyen siempre al menos algún elemento ornamental o instrumental (por ejemplo, Huerta de Arriba, Coruña del Conde, Ría de Huelva, Hío, Llavorsí) a excepción del de Bembibre (León) formado por 29 puntas de lanza de enmangue tubular. Otros depósitos que podemos considerar exclusivamente de armas tienen un número reducido de piezas, como los de Castromucho ( 3 puntas de lanza) y Cisneros (5 puntas de lanza) en Palencia o Laguna de Alcayán (3 puntas de lanza) en A Coruña (Ruiz Gálvez, 1984).

Las espadas aparecen generalmente de forma individual y en unos pocos casos se trata de dos ejemplares como en Herrera (Sevilla) ${ }^{2}$, incluso cuando se encuadran en depósitos más numerosos no suele haber más de un ejemplar de espada, salvo en la Ría de Huelva. Para citar conjuntos exclusivos de espadas tenemos que remontarnos al Bronce Medio con el depósito de Cuevallusa o el de Guadalajara (Brandherm, 1998) ambos con tres ejemplares, número muy alejado del hallazgo de Puertollano.

No es el momento de disertar sobre el sentido y finalidad de estos depósitos, aunque en este caso el número y tipo de componentes, su estado de conservación y el contexto del hallazgo determina su carácter de ocultamiento, pero sin posible relación con los llamados depósitos de fundidor. En principio no parece estar asociado a ningún poblado, como algunos otros hallazgos, ya que el material no metálico recuperado en la excavación se adscribe al Calcolítico. No aparecen mezclados objetos de cronologías nítidamente diferentes que indiquen un almacenamiento a lo largo del tiempo y no hay signos de celebración de algún ritual (cenizas o huesos). Las causas y motivaciones del agrupamiento de estas piezas se nos escapan, aunque sería interesante metalografiar algunas de ellas ya que recientemente se han identificado procesos de calentamiento o de quemado previos a la deposición ritual de espadas del Bronce Final en lugares acuáticos. Este es el caso de las espadas de los depósitos de Wilburton y Duddingston y esporádicamente de otros depósitos fluviales ingleses (Bridgford, 1998).

Un factor que ayuda a explicar este tipo de depósitos es la propia ubicación geográfica de los hallazgos, aspecto tratado preferentemente por Fernández Rodríguez y Rodríguez de la Esperanza (2002). Aquí nos interesa destacar la propia configuración del depósito, formado por armas. Como explicación complementaria al factor geográfico ¿podría considerarse que la deposición exclusiva de armas tuviera relación con algún tipo de enfrentamiento o combate vinculado a una norma de respeto entre combatientes? Esta cuestión no deja de ser una especulación, aunque la ausencia de elementos no armamentísticos juega a su favor. Las fracturas, y en ciertos casos las profundas grietas o la curvatura de las hojas podrían obedecer a su uso. Solamente aquellas piezas que son producto de una reutilización conservan intacta su morfología modificada, ya que con anterioridad habrían fracturado por sus puntos débiles, ahora desaparecidos. La excepción a esta norma es la espada 1, que se encuentra integra. Todas ellas, excepto la 1,7 y 8 , tienen melladuras y filos deteriorados. En la 3 y la 5 se aprecian bien las melladuras y deformaciones producidas por golpeo con otro metal: su reducido tamaño no puede atribuirse a la pala mecánica que descubrió el conjunto, sino que podrían deberse al golpeo con otro elemento metálico. Tampoco se han recuperado en el conjunto los fragmentos de punta, hoja o guarda de las piezas incompletas como son la 4, 12 y 13 , aunque la $\mathrm{n}^{\mathrm{o}} 10$ con fracturas antiguas se encuentra bastante reconstruida.

Esta hipótesis sugiere una funcionalidad real de estas armas, aunque desde un punto de vista actualista su eficacia no pueda considerarse buena: su dureza suele ser muy variable y pocas veces es la optima. Pero el problema más grave es la alta posibilidad de rotura. La mala calidad de las coladas se debe a una tecnología de fundición inadecuada en la que los

2 En este caso los hallazgos estan separados en el tiempo, aunque parece que proceden del mismo lugar. 
mecanismos de desgaseo no están adecuadamente desarrollados, especialmente para piezas de cierta longitud. Sin embargo, en la valoración del papel de las espadas hay que fijarse en el contexto en el que se encuadran, sin armamento personal alternativo más eficaz. Su función de prestigio y como símbolo de poder debió estar sustentado por un exitoso uso como elemento de coerción, y por una posesión restringida dada la mayor dificultad técnica en su manufactura. Para Bridgford (1997) el auge de la espada en el Bronce Final indica un cambio hacia un tipo de combate en grupo y los depósitos exclusivos de armas pueden explicarse por la existencia de tabús sobre la reutilización de las armas del enemigo.

Ignacio Montero Ruiz, Macarena Fernández Rodríguez, Blanca Gómez Tubio y M. a Ángeles OnTALBA SALAMANCA.

Departamento de Prehistoria, Instituto de Historia, CSIC. C/ Serrano, 13 - 28001 MADRID.

\section{BIBLIOGRAFÍA}

BRANDHERM, D. (1998): «Algunas consideraciones acerca de la espada de Guadalajara. ¿Un excepcional depósito desarticulado del Bronce Medio de la Meseta?». Trabajos de Prehistoria, 55 (2): 177-184.

BRIDGFORD, S. (1997): «The first weapons devised only for war». British archaeology, 22.

BRIDGFORD, S. (1998): «Bristish Late Bronze Age Swords. The metallographic evidence». En C. Mordant, M. Pernot, V. Rychner (eds.): L'atelier du bronzier en Europe du XX au VIII siécle avant notre ère. Actes du colloque international Bronze'96 Neuchâtel et Dijon, II: Du minerai au métal, du métal à l'objet, Paris, CTHS: 205-216.

Consuegra, S., Montero, I. y Rovira, S. (1991): «Estudi Arqueometal.lúrgic del dipósit de Llavorsí». En J. Gallart: El dipósit de bronzes de Llavorsí, Pallars, Sobirá. Excavacions Arqueológiques a Catalunya, 10: 187-200.

CRADDOCK, P.T. y MEEKS, N.D. (1987): «Iron in ancient copper». Archaeometry, 29 (2): 187-204.

Delibes, G., Fernández ManZano, J., FontanedA, E. y Rovira, S. (1999): Metalurgia de la Edad del Bronce en el piedemonte meridional de la Cordillera Cantábrica. La colección Fontaneda. Arqueología en Castilla y León, monografías, 3.

DíAZ-Andreu, M. y Montero, I. (1998): Arqueometalurgia de la Provincia de Cuenca: Minería y metalurgia en la Edad del Bronce. Arqueología Conquense, 15. Excma. Diputación de Cuenca. Cuenca.

FERnÁndeZ RodríGuez, M. (2002): «El Bronce Final Atlántico en Ciudad Real: El Depósito de Puertollano». Revista de Arqueología, 252: 24-31.

FÉRnÁNDEZ RoDríGUEZ, M. (e.p.): «Un depósito de armas del Bronce Final en Puertollano (Ciudad Real). Actas de los II Encuentros de Arqueología en Molina de Aragón. El Bronce Final en la Meseta (Molina de Aragón, 20-22 abril de 2001).

FERnÁNDEZ RodríGueZ, M. y RodRíGuEZ DE LA EsPERANZA, M. J. (2002): Los depósitos de armas en el Bronce Final: un nuevo hallazgo en Puertollano (Ciudad Real). Trabajos de Prehistoria, 59 (2):

Hunt, M. (1997): Minería y metalurgia prehistóricas en Andalucía Occidental. Tesis doctoral inédita. Universidad de Sevilla.

MaXwell, J.A.; CAMPBell, J.L. y TeEsDale, W.J. (1995): «The Guelp PIXE software package». Nuclear Instruments and Methods, 95: 407-421.

MONTERO RUIZ, I. (2001): «Estudios sobre metalurgia antigua en la provincia de Toledo: el proyecto Arqueometalurgia de la Península Ibérica». II Congreso de Arqueología de la Provincia de Toledo. Vol. I: 275-301. Diputación Provincial de Toledo. 
NeEDHAM, S.P. (1998): «Modelling the flow of metal in the Bronze Age». En C. Mordant, M. Pernot, V. Rychner (eds.): L'atelier du bronzier en Europe du XX au VIII siécle avant notre ère. Actes du colloque international Bronze'96 Neuchâtel et Dijon, III: Production, circulation et consommation du bronze. Paris, CTHS: 285-307.

NORTHOVER, P. (1982): «The metallurgy of the Wilburton hoards». Oxford Journal of Archaeology, 1 (1): 69-109.

NORTHOVER, J.P. y RYCHNER, V. (1998): «Bronze Analysis: experience of a comparative programme». En C. Mordant, M. Pernot, V. Rychner (eds.): L'atelier du bronzier en Europe du XX au VIII siécle avant notre ère. Actes du colloque international Bronze' 96 Neuchâtel et Dijon, I: Les analyses de composition du métal: leur apport à l'archéologie de l'Âge du Bronze. Paris, CTHS: 19-40.

Ontalba SAlamanca, M.. (2001): Estudios Arqueométricos mediante Técnicas Nucleares. Tesis Doctoral, Universidad de Sevilla.

Ontalba Salamanca, M.Á.; Ager, F.J.; Ynsa, M.D.; Gómez-Tubío, B.M.; ResPaldiza, M.Á.; García LóPez, J.; Fernández-Gómez, F.; De La BANDera M.L. y Grime, G.W. (2001): «External microbeam setup at the CNA (Seville) and its application to the study of tartesic jewellery». Nuclear Instruments and Methods in Physics Research B, 181: 664-669.

OREJAS, A. y MONTERO, I. (2001): «Colonizaciones, minería y metalurgia prerromanas en el levante y sur peninsulares». En De la Mar y de la Tierra. Producciones y productos fenicio-púnicos. XV jornadas de arqueología fenicio-púnica (eivissa 2000).Treballs del Museu Arqueològic d’Eivissa i Formentera, 47: 121-159.

RoHL, B y NeEDHAM, S. (1998): The circulation of metal in the British Bronze Age: the application of lead isotope analysis. British Museum Occasional Paper, 102.

RoviRA, S. (1995): «Estudio arqueometalúrgico del depósito de la Ría de Huelva». En M. L. Ruiz Gálvez (ed.): Ritos de paso y puntos de paso. La Ría de Huelva en el mundo del Bronce Final europeo, Complutum Extra, 5: 33-57.

ROVIRA, S., MONTERO, I. y CONSUEGRA, S. (1997): La primeras etapas metalúrgicas en la Península Ibérica. I Análisis de materiales. Instituto Universitario Ortega y Gasset. Madrid.

RoviRA, S. y SANZ, M. (1983): «Estudio Arqueometalúrgico de las piezas metálicas de el Peñón de la Reina (Alboloduy, Almería)». Antropología y Paleoecología Humana, 3: 193-202.

Ruiz Gálvez, M. L (1984): La Península Ibérica y sus relaciones con el círculo cultural Atlántico. Tesis Doctoral. Universidad Complutense de Madrid. Colección Tesis Doctorales, $139 / 84$.

Ruiz Gálvez, M. L., ed. (1995): Ritos de paso y puntos de paso. La Ría de Huelva en el mundo del Bronce Final Europeo. Complutum - Extra 5, Madrid.

SCOTT, D. (1987): Metallography of ancient metallic artifacts. Summer Schools Press. Institute of Archaeology. Londres.

SIERRA, J. C. (1984): El depósito de Bronce de Samieira. Boletín Auriense, Anexo 2.

TYLECOTE, R.F. (1973): «Casting copper and bronze into stone moulds». Bulletin of Historical Metallurgy Society, 7 (1): 1-5.

TYLECOTE, R.F. y NoRTHOVER, J.P. (1990): «Metallographic study». En S.P. Needham: The Petters Late Bronze Age Metalwork. British Museum Occasional Paper, 70: 89-97. 